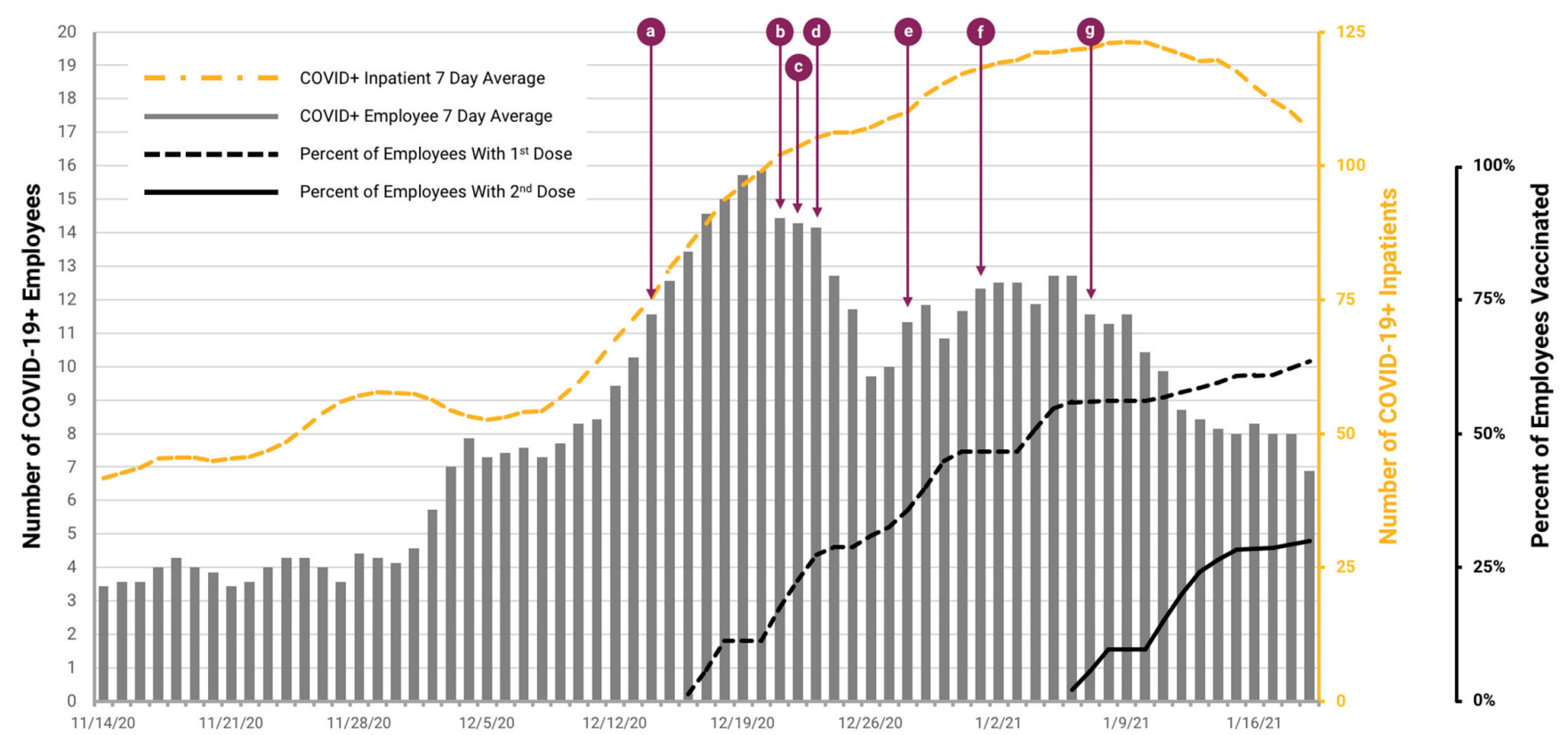

Fig. 1. Bar graph of 7-day average number of health system employees with positive SARS-CoV-2 tests from November 14, 2020, to January 19, 2021. Yellow dashed line is 7-day average number of COVID-19-positive inpatients over the same period. The black dashed line represents the percentage of total health system employees who received first dose of Pfizer anti-SARS-CoV-2 vaccine, beginning December 16, 2020. The black solid line represents the percentage of total health system employees who received second dose of Pfizer anti-SARS-CoV-2 vaccine, beginning January 6, 2021. Other interventions are as follows: (a) December 14, 2020: reduced adult visitors from 2 to 1; (b) December 21, 2020: required face shields and surgical mask for all patient encounters and restricted cafeteria seating; (c) December 22, 2020: employees to confirm symptom free upon arrival; (d) December 23, 2020: employees to use surgical masks in all areas; (e) December 28, 2020: employee temperature screening on arrival; (f) January 1, 2021: 50\% ambulatory visits changes to telehealth; and (g) January 8, 2021: full adult visitor restriction.

2. Polack FP, Thomas SJ, Kitchin N, et al. Safety and efficacy of the BNT162b2 mRNA COVID-19 vaccine. N Engl J Med 2020;383:2603-2615.

3. Baden LR, El Sahly HM, Essink B, et al. Efficacy and safety of the mRNA-1273 SARS-CoV-2 vaccine. N Engl J Med 2020. doi: 10.1056/NEJMoa2035389.

4. Infection control guidance for healthcare professionals about coronavirus (COVID-19). Centers for Disease Control and Prevention website. https://www.cdc.gov/coronavirus/2019-ncov/hcp/infection-control.html. Published 2020. Accessed February 8, 2021.

5. Wood S, Schulman K. Beyond politics-promoting COVID-19 vaccination in the United States. N Engl J Med 2021. doi: 10.1056/NEJMms2033790.

\title{
Level of respiratory protection for healthcare workers caring for coronavirus disease 2019 (COVID-19) patients: A survey of hospital epidemiologists
}

Winston L. McCormick BS ${ }^{1}$ (D), Michael P. Koster MD ${ }^{1,2}$, Geetika N. Sood MD, ScM ${ }^{3}$ and Leonard A. Mermel DO, ScM ${ }^{1,2}$ ${ }^{1}$ Warren Alpert Medical School of Brown University, Providence, Rhode Island, ${ }^{2}$ Division of Infectious Diseases, Department of Epidemiology \& Infection Control, Rhode Island Hospital, Providence, Rhode Island and ${ }^{3}$ Division of Infectious Diseases, Department of Epidemiology \& Infection Control, Johns Hopkins Bayview Medical Center, Baltimore, Maryland

To the Editor-Appropriate personal protective equipment (PPE) for healthcare workers (HCWs) caring for patients with coronavirus disease 2019 (COVID-19) has not yet been completely

\footnotetext{
Author for correspondence: Dr Leonard Mermel, E-mail: lmermel@lifespan.org Cite this article: McCormick WL, et al. (2022). Level of respiratory protection for healthcare workers caring for coronavirus disease 2019 (COVID-19) patients: A survey of hospital epidemiologists. Infection Control \& Hospital Epidemiology, 43: 681-683, https://doi.org/10.1017/ice.2021.74
}

elucidated nor universally standardized. In areas where severe acute respiratory coronavirus virus 2 (SARS-CoV-2) community transmission is moderate or substantial, the Centers for Disease Control and Prevention (CDC) recommends at least N95 respirator protection, eye protection, gowns, and gloves for patient-facing HCWs. The lack of a centralized national process for the acquisition and stockpiling of PPE has resulted in severe shortages across the United States, forcing competition among hospital systems and leading to extreme measures to procure PPE for HCWs. ${ }^{1,9}$

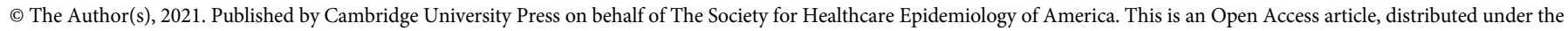

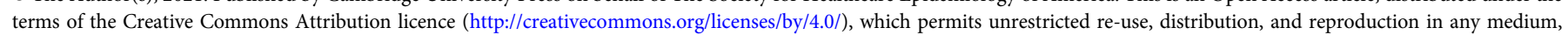
provided the original work is properly cited. 
Table 1. Personal Protective Equipment (PPE) Use Among Respondent Hospitals and Hospital Systems

\begin{tabular}{|c|c|c|c|c|}
\hline Hospital & $\begin{array}{l}\text { Respiratory PPE Used } \\
\text { While Caring for Patients } \\
\text { With Confirmed or } \\
\text { Suspected COVID-19 }\end{array}$ & $\begin{array}{l}\text { Respiratory PPE for } \\
\text { General Patient Care }\end{array}$ & Respiratory PPE Use for AGPs & Retest COVID-19 Patients \\
\hline $\begin{array}{l}\text { Non-VA hospitals or } \\
\text { health systems } \\
(n=24)\end{array}$ & $\begin{array}{l}\text { N95 respirator }(n=15) \\
\text { Surgical mask }(n=9)\end{array}$ & $\begin{array}{l}\text { N95 respirator }(n=2) \\
\text { Surgical mask }(n=20)\end{array}$ & $\begin{array}{l}\text { N95 respirator, regardless of } \\
\text { SARS-CoV-2 status }(n=20) \\
\text { Surgical mask if known negative } \\
\text { SARS-CoV-2 test }(n=2)\end{array}$ & $\begin{array}{l}\text { Yes, if symptomatic }(n=10) \\
\text { Yes, if before procedures }(n=11) \\
\text { Yes, every } 5 d(n=1) \\
\text { Yes, on day } 5 \text { if from high risk setting } \\
\quad(n=1) \\
\text { Yes, every } 3 d \text { if in multiroom or } \\
\text { behavioral health unit }(n=1)\end{array}$ \\
\hline $\begin{array}{l}\text { VA hospitals or health } \\
\text { systems } \\
(n=5)\end{array}$ & $\begin{array}{l}\text { N95 respirator }(n=4) \\
\text { Surgical mask }(n=1)\end{array}$ & $\begin{array}{l}\text { N95 respirator }(n=0) \\
\text { Surgical mask }(n=4)\end{array}$ & $\begin{array}{l}\text { N95 respirator, regardless of SARS- } \\
\text { CoV- } 2 \text { status }(n=2) \\
\text { Surgical mask if known negative } \\
\text { SARS-CoV- } 2 \text { test }(n=1)\end{array}$ & $\begin{array}{l}\text { Yes, if symptomatic }(n=3) \\
\text { Yes, if before procedures }(n=1)\end{array}$ \\
\hline
\end{tabular}

Note: COVID-19, coronavirus disease 2019; SARS-CoV-2, severe acute respiratory coronavirus virus 2; APGs, aerosol-generating procedures.

Infection control departments have developed triage plans for PPE use in the face of uncertain and insufficient supplies in an effort to mitigate COVID-19 risk among HCWs and hospitalized patients. Recommendations were often based on intuition and extrapolation of data from other respiratory viral infections, especially as it relates to respiratory protection. Studies of influenza and seasonal coronavirus virus have revealed that surgical masks are not inferior to N95 respirators for source control. ${ }^{2,45,7,8}$ Studies of SARS-CoV-1 have demonstrated no significant difference between surgical masks and N95 respirators with respect to protection of exposed HCWs. ${ }^{3,7}$ Surgical masks for patient source control and worn by HCWs, especially coupled with HCW use of face shields, protect HCWs involved in routine COVID-19 patient care who are not participating in aerosol-generating procedures (AGPs). ${ }^{5,6}$ Given that N95 respirators are superior to surgical masks in protecting the user from inhalation of small-particle aerosols, their use has been typically reserved for AGPs. ${ }^{2,4,5}$

\section{Methods}

On October 6, 2020, we performed an online survey of infection control leaders regarding their respiratory PPE policies for general routine patient care, general care of patients with confirmed or suspected COVID-19, and care for patients undergoing AGPs. In addition, we asked whether routine retesting of admitted patients was performed at some interval after admission.

\section{Results}

Of the 56 hospitals or health systems, 29 responded (52\% response rate); 5 were with the Department of Veterans' Affairs (VA) (Table 1). The sites were located in or included Providence, Rhode Island; Omaha, Nebraska; Denver, Colorado; Charlottesville, Virginia; Charlotte, North Carolina; Royal Oak, Michigan; Chicago, Illinois; Boston, Massachusetts; Ann Arbor, Michigan; St. Louis, Missouri; Salt Lake City, Utah; Baltimore, Maryland; Pittsburgh, Ohio; Cleveland, Ohio; San Francisco, California; New York City, New York; Iowa City, Iowa; Dallas, Texas; Buffalo, New York; San Antonio, Texas; Montreal, Quebec, Canada; the VISN-10 network of VA hospitals; as well as VA systems in Texas, Connecticut, and New York.

Variability in respiratory PPE was reported in the care of patients with proven or suspected COVID-19. Overall, 63\% of
non-VA hospitals or health systems used N95 respirators when caring for such patients. There was greater consistency among VA respondents, with $80 \%$ using N95 respirators when caring for patients with proven or suspected COVID-19. Not all hospitals or hospital systems used N95 respirators during AGPs. Some (33\% of VA respondents and $8 \%$ of non-VA respondents), adopted a strategy for use of surgical masks during AGPs in patients negative for SARS-CoV-2. Notably, 27 of 29 respondents to a question about eye protection affirmed such use when caring for patients with COVID-19. There was no consistency in the recommendations reported regarding the retesting of patients.

\section{Discussion}

Definitive data are still lacking regarding the necessary and sufficient PPE when caring for patients with COVID-19, during AGPs, and while providing routine patient care in a pandemic fraught with high asymptomatic case loads. As such, the variability we found in PPE use suggests that more data are required to fully understand SARS-CoV-2 transmission routes to inform appropriate universal PPE recommendations. A limitation of this survey is that we did not ask what PPE would be recommended if resource limitations did not exist. Every hospital and hospital system had to develop local guidance based on local resources, and our survey does not capture this. We do know that supplies have yet to meet demands.

Transmission risk is also dependent on source control of suspected and asymptomatic patients, and unfortunately, we did not ask about this important infection prevention strategy in our survey. We did ask about retesting of admitted patients as an infection control practice, and we found wide variability, likely reflecting both limitations of testing resources as well as lack of data for utility of this practice.

December 2020 ushered in a new phase of the COVID-19 pandemic. Two vaccines were given FDA emergency use authorization, and the new, more highly transmissible B117 variant was discovered on American shores. ${ }^{10}$ The B117 strain appears to be more contagious, and while we wait on official CDC and World Health Organization (WHO) guidance, current COVID-19 guidelines for PPE and vaccinations appear to be sufficient. ${ }^{10}$ Hospital epidemiologists will need to continue to assimilate evolving evidence to best protect HCWs from contracting COVID-19 in the face of a continuing pandemic and 
ongoing supply-chain shortages. Further elucidation of transmission dynamics will assist infection control departments facing ongoing PPE shortages and emerging SARS-CoV-2 mutant strains of this RNA virus.

In conclusion, most hospitals and hospital systems responding to our survey use N95 respirators when caring for patients with proven or suspected COVID-19 and when aerosol-generating procedures are performed. While we await WHO and CDC guidance on how vaccines and highly transmissible mutant strains will affect PPE recommendations, the 2 opposing forces will likely draw out the need for enhanced PPE in healthcare settings.

Acknowledgments. We thank the colleagues who kindly responded to our survey with institution-specific or system-wide data.

Financial support. No financial support was provided relevant to this article.

Conflicts of interest. All authors report no conflicts of interest relevant to this article.

\section{References}

1. Artenstein AW. In pursuit of PPE. N Engl J Med 2020;382(18). doi: 10.1056/ nejmc2010025.
2. Bartoszko JJ, Faroogi MA, Alhazzani W, et al. Medical masks vs N95 respirators for preventing COVID-19 in healthcare workers: a systematic review and meta-analysis of randomized trials. Influenza Other Respir Viruses 2020;14:365-373.

3. Doremalen NV, Bushmaker T, Morris DH, et al. Aerosol and surface stability of HCoV-19 (SARS-CoV-2) compared to SARS-CoV-1. N Engl J Med 2020;382:1564-1567.

4. Leung NH, Chu DK, Shiu EY, et al. Respiratory virus shedding in exhaled breath and efficacy of face masks. Nat Med 2020;26:676-680.

5. Mermel LA. Respiratory protection for healthcare workers caring for COVID-19 patients. Infect Control Hosp Epidemiol 2020;41:1064-1065.

6. Ng K, Poon BH, Puar TH, et al. COVID-19 and the risk to health care workers: a case report. Ann Intern Med 2020;172:766-767.

7. Seto W, Tsang D, Yung R, et al. Effectiveness of precautions against droplets and contact in prevention of nosocomial transmission of severe acute respiratory syndrome (SARS). Lancet 2003;361:1519-1520.

8. Sickbert-Bennett EE, Samet JM, Clapp PW, et al. Filtration efficiency of hospital face mask alternatives available for use during the COVID-19 pandemic. JAMA Intern Med 2020;180:1607-1612.

9. Woolley K, Smith R, Arumugam S. Personal protective equipment (PPE) guidelines, adaptations and lessons during the COVID-19 pandemic. Ethics Med Public Health 2020. doi: 10.1016/j.jemep.2020.100546.

10. Galloway SE, Paul P, MacCannell DR, et al. Emergence of SARS-CoV-2 B.1.1.7 lineage-United States, December 29, 2020-January 12, 2021. Morb Mortal Wkly Rep 2021. doi: 10.15585/mmwr.mm7003e2external icon.

\title{
Effectiveness of personal protective equipment-Yes, the buck and virus can stop here
}

\author{
Alan C. Howell MD ${ }^{1}$ (1), Lisa Havens JD², Wes Swinford ${ }^{2}$ and Alejandro C. Arroliga MD \\ ${ }^{1}$ Division of Infectious Disease, Department of Internal Medicine, Baylor Scott and White Health, Temple, Texas, ${ }^{2}$ Risk Management, Baylor Scott and White \\ Health, Temple, Texas and ${ }^{3}$ Baylor Scott and White, Temple, Texas
}

To the Editor-Coronavirus disease 2019 (COVID-19) has adversely affected the health and well-being of our communities as well as our places of work in countless ways. Healthcare providers (HCPs) across the country continue to step forward in support of their communities and families. These workers are a critical yet finite resource. Thus, it is important they and the systems in which they work take the appropriate steps to prevent severe acute respiratory coronavirus virus 2 (SARS-CoV-2) exposure and COVID-19. Herein, we discuss our experience as a healthcare system regarding the effectiveness of personal protective equipment (PPE) and the sources of exposure.

Baylor Scott and White Health (BSWH) is the largest not-for-profit healthcare system in Texas and one of the largest in the United States. Our system includes 52 hospitals, 7,300 active physicians, and 42,000 employees. Since the pandemic began, system recommendations regarding the use and type of PPE have remained consistent with guidance provided by the Centers for Disease Control and Prevention (CDC). Additionally, BSWH set up an Employee Health COVID Command Center (EHCCC) in early 2020. The purpose of the EHCCC was to have 1 centralized contact for employees with questions

Author for correspondence: Alan C. Howell, E-mail: alan.howell@bswhealth.org

Cite this article: Howell AC, et al. (2022). Effectiveness of personal protective equipment-Yes, the buck and virus can stop here. Infection Control \& Hospital Epidemiology, 43: 683-684, https://doi.org/10.1017/ice.2021.75 about exposures, travel, symptoms, testing, medical leave, and pay. Both patient and community encounters were reported to the EHCCC. The EHCCC created and maintained a single database for monitoring trends and developing reports. Other responsibilities of the EHCCC included fit testing as well as managing the exemption requests and return-to-work issues to maintain safe work environments for staff and patients. EHCCC collaborated with infection control and clinical leaders on providing guidance and developing protocols.

As of August 31, 2020, 12,405 employees had had direct exposure to SARS-CoV-2-positive patients due to their job duties. Moreover, 1,639 of these employees were tested for SARS-CoV-2 based upon the nature of their exposure and/or onset of symptoms consistent with COVID-19. Testing was performed using a nasal swab and a nucleic acid amplification test (NAAT). Overall, 87 employees tested positive. Our observed conversion rate was $0.70 \%$ by encounter and $0.20 \%$ by total staff. The median time from COVID-19 patient exposure to positive employee test was 11 days. Finally, between March and August, the greatest number of positive SARS-CoV-2 tests occurred in April, when 54 employees tested positive. Thereafter, the number of positive tests dropped precipitously, and for July and August, the number of positive tests were 3 and 1 , respectively.

During this same period, 7,486 employees reported community exposures. 3,990 of these employees were tested due to their described exposure and/or onset of COVID-19 symptoms. Moreover, 1,136 tested

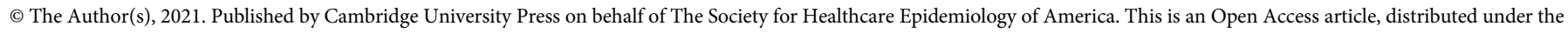
terms of the Creative Commons Attribution licence (http://creativecommons.org/licenses/by/4.0/), which permits unrestricted re-use, distribution, and reproduction in any medium, provided the original work is properly cited. 